\title{
Creative cities and regions: The case for local economic diversity
}

article version: accepted manuscript

Leppälä, Samuli

Desrochers, Pierre

Desrochers, P., \& Leppälä, S. (2011). Creative cities and regions: The case for local economic diversity. Creativity and Innovation Management, 20(1), 59-69. Doi: 10.1111/j.1467-8691.2010.00586.x

\footnotetext{
"This is the peer reviewed version of the following article: Desrochers, P. and Leppälä, S. (2011), Creative Cities and Regions: The Case for Local Economic Diversity. Creativity and Innovation Management, 20: 59-69, which has been published in final form at doi:10.1111/j.1467-8691.2010.00586.x. This article may be used for non-commercial purposes in accordance with Wiley Terms and Conditions for Self-Archiving."
}

\section{HOW TO CITE TSPACE ITEMS}

Always cite the published version, so the author(s) will receive recognition through services that track citation counts, e.g. Scopus. If you need to cite the page number of the TSpace version (original manuscript or accepted manuscript) because you cannot access the published version, then cite the TSpace version in addition to the published version using the permanent URI (handle) found on the record page. 


\section{Creative Cities and Regions: The Case for Local Economic Diversity.}

\section{Abstract}

In their recent discussion of the Richard Florida and Jane Jacobs-inspired "creative cities" policy literature, Hospers and Pen (2008) argue that despite increasingly more effective 'space shrinking' technologies, cities remain among the most suitable locations for creative activities of all types. This paper supplements their contribution by documenting more concretely how economically diversified cities provide a fertile environment for the discovery and development of new technological combinations. Along the way, it is shown how understanding of the link between creativity and urban agglomeration benefits from a multidisciplinary approach, which studies neither phenomenon in isolation.

\section{Introduction}

Cities (or nowadays metropolitan areas) ${ }^{1}$ have long been recognized as primary cradles of artistic and other advances, but much debate remains as to the causality link between urbanization and economic development processes (Hall, 2000; Lampard, 1955; Polese, 2005). In their recent discussion of the Richard Florida (2002; 2005; 2008) and Jane Jacobs (1969) -inspired "creative cities" policy literature (Scott 2006), Hospers and Pen (2008, p. 259) build on a "geography of innovation" literature mostly known to management scholars through Michael Porter's (1990) The Competitive Advantage of Nations to argue that urban agglomerations are the primary engines of economic development because they are locations "where knowledge, creativity and innovation flourish." This scholarship emphasizes the commonsensical notions that innovation activities within firms are interactive learning processes that often involve outside actors (potentially including individuals working for other firms or educational institutions); that innovative small firms especially benefit from being embedded in regionally-based networks of similarly innovative firms; and that so-called 'knowledge spillovers' and the communication of tacit knowledge remain heavily dependent on face-to-face interactions and are therefore especially sensitive to the friction of geographical space (Clark et al., 2000; Polese, 2005).

Few scholars in this line of inquiry, however, have looked up the work of students of human creativity. It is probably fair to say that the few who did found it of little relevance in terms of explaining why historically cities such as Athens, Florence, London, Paris and

1 A metropolitan area includes not only the population of a well-known political entity (say, Paris, London or New York), but also its suburban, exurban and sometimes surrounding rural populations, all of whom are part of the same economic entity in terms of employment, transportation, and commerce. 
New York were for a time hotbeds of creative thinking and innovation. This assessment was perhaps best expressed by a major figure in the field of urban studies, Sir Peter Hall (2000: 642), who observed a decade ago that "in the vast literature on creativity," there is little that is of relevance to his corner of academia "because virtually none of it addresses the question of location. Psychologists and psychoanalysts treat it almost exclusively in terms of the individual personality; so do students of management, who have looked at company innovation. Few studies mention the social context; even fewer are specific."

While Hall makes a valid point, it is worth noting that the geography of innovation literature has itself been criticized on several counts ranging from the fact that it is built on ill-defined and overlapping concepts or frameworks (from 'industrial districts,' 'innovative milieux' and 'clusters' to 'learning regions,' 'regional innovation systems' and 'techno-regions') and that its contributors tend to neglect human agency by unduly emphasizing instead the role of "networks" or "milieux" as active agents. It has also been increasingly recognized that geographical proximity is neither a necessary nor a sufficient condition for innovation and learning to occur and that many innovative activities involve the collaboration of employees of the same multinational firms (or their suppliers or research partners) based in different geographical locations, a process often conveyed by the expression "global pipelines" which is contrasted to the "local buzz" of individuals in close physical proximity of one another (Boschma, 2005; Moulaert and Sekia, 2003; Simmie, 2005). Despite conceptual and theoretical problems, however, it cannot be denied that some of the key processes emphasized in this literature, most notably that urban agglomerations greatly facilitate frequent face-to-face interactions between individuals belonging to different organizations and that some places are more conducive to entrepreneurial activities and innovative behavior than others, are undoubtedly real and important. As such, the world is far from being "flattened" by new information and transportation technologies and locating in certain areas rather than others can still deliver some important economic benefits.

Our main goal in this paper is to show a road to mutual enrichment between the "geography of innovation" and "creativity and innovation management" literatures. We do so by discussing and illustrating the inherent benefits of a more diversified local economic structure for innovative behavior, a stance which goes against the long standing pro-regional specialization prescription of traditional economic analysis. Our paper is structured as follows. First, we briefly cover the economic rationale of urban agglomerations and highlight how such settings can facilitate innovative advances and entrepreneurial activities. This is followed by a presentation of the advantages most commonly associated with a more diversified local economic structure and, through theoretical insights well-known to readers of this journal and additional illustrative case illustrations derived from a qualitative survey of Canadian individual inventors, of the specific mechanisms and patterns through which entrepreneurial ventures and established plants located in such contexts can more easily and "spontaneously" benefit from ideas and know-how used in other lines of work. Unveiling these processes, we argue, gives us a more comprehensive understanding of how a given location can facilitate analogical thinking (Gassmann and Zeschky, 2008) and new product development (Song et al., 1997; Ernst, 2002) at both the individual and firm level. 


\section{Urbanization and Economic Development}

The systematic study of business location decisions and regional development processes has for more than a century generated a voluminous literature in disciplines ranging from geography, economics, and urban planning to engineering, management, political science and sociology. Analysts have generally sought to develop theories in response to three empirical observations: 1) a large portion of world output is produced in a limited number of highly concentrated core regions; 2) firms in similar or related industries tend to colocate in particular places; and 3) both of these patterns appear to be sustainable over time. This outcome has typically been attributed to what are now termed 'agglomeration economies,' i.e., the economic benefits that individuals and firms obtain when locating near one another, including shared infrastructures and suppliers.

Several authors, however, have also long observed that the geographical concentration of numerous human beings greatly facilitates sustained face-to-face interactions and creates a social environment that is most conducive to innovative behavior. For example, the French economist Frederic Bastiat (2007/1850: 103) wrote more than a century and a half ago that the "density of population not only enables us to reap more advantage from the machinery of exchange, it permits us to improve that machinery, and increase its power." Indeed, he added, "on leaving the metropolis for a time, and going to reside in a small provincial town, one is astonished to find that in many instances the most ordinary services can only be obtained at great expense, and with time and difficulty" (idem). Large concentrations of people also gave humans "more facility in dividing their employments, in uniting their powers, and in combining to found churches and schools, to provide for their common security, to establish banks and insurance companies, in a word, to procure themselves all the common enjoyments with a much smaller proportion of efforts" (idem: 104). Decades later, the social reformer Frederic C. Howe (1915: 1), an author whose stance on economic issues was in direct opposition to that of Bastiat, similarly observed that education, culture, a love of fine arts, science, invention and industry had always "coincided with a highly developed city life" because urbanization allowed a greater division of labour which in turn created "the wealth which such division makes possible." Of course, "the larger the city and the more minute the specialization, the greater the co-operation and the more easy [sic] the production of wealth." Arguably the most lasting contribution among early analysts is the economist Alfred Marshall's (1920/1890) concept of an 'industrial district.' Besides mentioning the external benefits that single-activity or closely related producers derive from sharing the fixed costs of such common resources as specialized infrastructure and services, skilled labour pools and specialized suppliers, Marshall emphasized that through co-location and frequent interaction, producers share a common knowledge base, learn from and continuously build on each other's advances. Numerous other scholars at the time made similar observations and highlighted the self-reinforcing nature of innovative processes in large urban agglomerations (Krzyzanowski, 1927).

By the middle of the twentieth century, however, technological changes, economic growth and their resulting enhancement of labour and entrepreneurial mobility had led 
most analysts to conclude that the type of geographically concentrated industries identified by Marshall and others had "become increasingly rare" while, by contrast, "external economies on the broader basis of urban size and diversity [had] remained a powerful locational force" (Hoover and Giarratani, 1984/1970, p. 121). Furthermore, the development and/or refinement of analytical (mathematical) tools in which innovation was treated as a taken-for-granted black box resulted in the increased dominance of mechanistic and static 'resources allocation' or 'location scanning' perspectives among urban and regional scholars.

These theoretical approaches, however, proved unable to account for the spontaneous and spectacular rise in the 1970s and 1980s of a number of regions, including Silicon Valley and Route 128 in the United States, as well as the so-called Third Italy, whose main characteristics were the spatial clustering of related, highly innovative and (for the most part) relatively small firms. Scholars in numerous disciplines thus began to (re)discover and further develop more qualitative and dynamic concepts and insights in an attempt to explain how the industrial and social characteristics of a given place (ranging in scale from streets to cities and regions) provide (or not) fertile soil for innovative behaviour, along with the continued relevance of dense and localized networks of small innovative firms. Of course, several of the realities described by academic researchers were well understood by successful businesspeople. To give but one illustration, the scientist/entrepreneur Ralph Landau (1996: 2) attributed the success of his small R\&D organization to the fact that it was located in the Greater New York City area, thereby allowing his employees to benefit from an "extremely cosmopolitan perspective" and "many of the features that only a large city can offer." He added:

In fact, the kind of person who is attracted to New York is very often the kind who would not fit into the culture of a large company. For New York one can substitute few other major cities in the United States. Nevertheless, research organizations are often located on predominantly semi-rural or rural campuses where it is supposed that people can think more effectively. I have often felt that this is not always so and that the research environment for an industrial organization requires a feeling of intense energy - even pressure and the knowledge that there are important problems that must be solved every day (idem).

Fundamentally, the recent geography of innovation literature asks two questions: 1) Why are some regions more innovative than others?; and 2) How does a specific location influence the continuous upgrading of firm capabilities? The answers most commonly provided still revolve around the importance of geographical proximity between actors, which greatly facilitate formal and informal collaborations between firms (be they potential competitors or in a user-producer relationship) and/or between firms and research institutions; the spin-off of new firms; and the transmission of tacit knowledge (through frequent face-to-face interactions and the interfirm mobility of skilled workers). The case made on behalf of each factor is now briefly described. 
Local linkages and collaboration: Geographical proximity, because of the frequent interactions and long-term contracts or commitments between people that it allows (whether in working environments or in social activities), is often said to play a crucial role in building the trust bonds that are needed to share sensitive information and develop a successful customer-supplier relationship. Lissoni (2001) refers to these linkages as "epistemic communities" within which information is circulated.

Spin-off formation: Entrepreneurship, especially in terms of employees creating new firms in close proximity to former employers (so-called "spin-offs" or "start-ups"), is said to be greatly facilitated in some regional contexts (Breschi and Malerba, 2001). On the one hand, an entrepreneurial culture in which individuals continually leave their employers to launch new firms provides ample demonstration effect which further reinforces this tendency. On the other, localized industries provide easy access to specialized labour, inputs and customers which, along with the presence of knowledgeable investors, further facilitates the launch of innovative firms. Spin-offs also tend to create a local or regional environment in which individuals working for different organizations interact more with one another than would otherwise be the case.

Tacit knowledge: The more specialized and innovative an activity is, the more likely it is to be geographically concentrated. The more standardized it becomes, the more it tends to migrate toward customers or inputs. This pattern can be attributed in part to the fact that the crucial knowledge in any innovative industry is not standardized information, routine patterns or the public knowledge of science, but rather what is new, what are the latest changes, and the specialized know-how that individuals have acquired through practice and mistakes. Thus, knowledge from which innovations stem is not freely available, thereby providing firms that locate near its sources a competitive advantage. As such, globalization and improvements in telecommunication technologies have not crowded out the need for proximity, but conversely have strengthened it in cases where crucial knowledge is only available locally (Audretsch, 2003; Gertler, 2003). And even though most of the suppliers and customers of a firm might be located outside of its regional setting, being located in an innovative area typically allows creative and entrepreneurial individuals to absorb thinking processes, along with specialized know-how and ways of doing things, while also increasing the probability of useful informal encounters (Cohen and Levinthal, 1990; Nooteboom, 2000). Such a setting also makes it easier for entrepreneurs, managers and technicians to monitor emerging technologies closely and to find answers to their questions more rapidly, in the process lessening the probability of being caught off guard by new breakthroughs.

While much evidence points toward the continued importance of geographical location for fostering creativity and innovation in some specific contexts, this argument should be handled more cautiously than it often is for reasons ranging from the 'fuzziness' of the main concepts used in the 'geography of innovation' literature; the continued importance of both traditional agglomeration economies and non-regional networks and linkages in explaining the locational decisions and practices of countless firms; and the fact that individuals born in or enjoying less advantageous locations are sometimes able to overcome geographical disadvantages (Boschma, 2005; XXX). Perhaps most problematic, 
however, is that the geography of innovation literature has, by and large, remained confined to the study of innovation within one line of work and has thus fact neglected the processes underlying the cross-fertilization of know-how across different lines of work and the facilitating role that a more diversified local economic base might play in this respect. We will turn our attention to this issue after having first summed up the other well-known advantages of diversified local economy.

\section{Local Diversity and Economic Resilience}

Following David Ricardo's writings on comparative advantage, most economic analysts have considered the local specialization of economic activities as both a natural and desirable outcome of trade liberalization. By concentrating on the production of what they do relatively better than others and through subsequent exchange, all individuals (and regions) enjoy a greater standard of living than if they were attempting to produce a wider range of goods and services in their local community. Regional economic specialization is also said to allow producers to tap into the types of formal and informal assets discussed in the previous section (Porter, 1990).

However, as Marshall (1920, p. 273) wrote several decades ago, "a district which is dependent chiefly on one industry is liable to extreme depression, in case of a falling-off in the demand for its produce, or of a failure in the supply of the raw material which it uses"; an outcome which still seems unavoidable (Chapman, 2005). Not surprisingly, Marshall (idem) observed that this problem was "in a great measure avoided by those large towns or large industrial districts in which several distinct industries are strongly developed." Hoover and Giarratani (1984, chapter 12, non-paginated) similarly pointed out that regional economic diversification had long been viewed as a "healthy" structural feature worth striving for" although "the grounds for this view... have never been clearly articulated." In their opinion, this case can be traced back to the assumption that "a region with a diversified structure (many different kinds of activities and an absence of strong specialization) is necessarily less vulnerable to cyclical swings of general business conditions and demand" and that multiple employment and investment opportunities create more opportunities for workers, entrepreneurs and investors, thus providing "a better chance for new kinds of business to get a start and to survive the hazardous years of infancy." It has also long been held that a more diversified local economy inherently enjoys a greater "multiplier effect" when new activities are added to existing ones, at least inasmuch as a greater range of local suppliers are likely to be called upon. ${ }^{2}$

While the previous arguments have long been discussed, in the last two decades a new consideration has increasingly been raised in policy discussions. In short, spurred by economists Robert Lucas (1988) and Ed Glaeser et al. (1992) who traced the insight back to urban theorist Jane Jacobs (1969), several researchers have attempted to assess whether or not internally diverse regions might be better incubators of innovative activities. These researchers, however, have typically limited their analysis of "Jacobs

2 Of course, a specialized region can experience faster and more significant employment and wealth creation than a more diversified local economy when there is a high demand for its main product. 
spillovers" to the idea that a more diversified local economy inherently promotes the diffusion of ideas across different lines of work despite the fact that Jacobs' framework is broader and puts much more emphasis on the importance of traditional urbanization economies for entrepreneurial activities. While there is now no lack of statistical research on localized knowledge spillovers, there is, however, a general concern that the econometric studies that link together regional measures, such as the degree of economic specialization and growth, do not yield any direct proof of the very existence of knowledge spillovers (Beaudry and Schiffauerova, 2009; Breschi and Lissoni, 2001; Hansen, 2002). We now turn to a more in-depth discussion of this subject.

\section{Local Diversity, Human Creativity and Jacobs Spillovers}

\section{Local Diversity and Human Creativity}

As stated above, the basic idea underlying 'Jacobs spillovers' is that the crucial knowhow underlying technical advances do not come from the reuse or diffusion of knowledge among competitors in similar lines of work, but rather from different activities. In other words, while creative individuals can be found in all locations, they are faced with more numerous and different kinds problems and given more opportunities to address them in more economically diverse environments, especially in terms of being able to interact with people that possess different expertise than their own. Therefore, besides the creativity and innovation management activities taking place as a matter of course in firms, more diversified local economies are inherently more likely than more specialized ones to foster innovative behavior and activities within corporate settings. If true, strategic location decisions should therefore factor in to some extent considerations other than traditional factors such as input (labor, energy, etc.) availability, proximity to markets, transport infrastructure, taxation and regulations.

Of course, the fact that all innovations are the result of new combinations of pre-existing and different know-how, skills, ideas, processes, materials and artifacts has long been known and discussed by both students of human creativity and technological innovation. It has also long been recognized that multidisciplinary teams most efficiently link concepts developed in one technological area to problems arising in another by helping individuals overcome the blinders created by their particular expertise (Babbage, 1832; Carter, 1939; Fores, 1979; Schroeder et al., 1989; Twiss, 1980). ${ }^{3}$ Conversely, the typical pitfall of a highly specialized local economy on the creative potential of its inhabitants was obvious to Keir (1919, p. 47) almost a century ago:

3 Not surprisingly in light of the importance of new combinations in any creative act, some social scientists have addressed the interindustrial diffusion of technological know-how through frameworks and concepts such as "technological convergence," "technoeconomic paradigms," "general purpose technologies" and recombinant growth" (Lipsey et al., 2005; Weitzman, 1998), while students of human creativity have written extensively on 'associative ability,' 'bisociation,' 'lateral thinking' and 'analogical reasoning,' among others (Berkun, 2007; Csikszentmihalyi, 1997; de Bono, 1992; Kaufmann, 2004; Koestler, 1964; Sternberg, 1999; Weber and Perkins, 1992). 
From the point of view of employees, [geographically-specialized] localization is bad because it also tends toward narrowing the minds of the townspeople. A young man brought up in Fall River [Massachusetts], say, has but little choice of occupation; he must become a weaver or a loom-fixer or some other artisan connected with cotton manufacture, because by upbringing, education and example he is forced into that path, and furthermore he goes to work at an early age. It may happen that many a square peg is rammed into a round hole in this way, or a life constricted which might under better conditions have expanded. There is something deadening to the human mind in uniformity; progress comes through variation, therefore in a town of one industry a young man loses the stimulus for self-advancement.

But while these points are well taken, very little has been written on the specific processes through which local economic diversity can actually facilitate innovative behavior. We now turn to our own attempt to document these processes.

\section{Jacobs Spillovers in the Canadian context}

To gain a better understanding of the circumstances through which local economic diversity can facilitate the development of new combinations of artifacts, ideas and skills, we set out to study individual inventors, for whom moving frequently between different lines of work and/or regularly borrowing ideas from fields other than their own seems to be a dominant characteristic. ${ }^{4}$ Two rounds of semi-structured interviews covering, among other subjects, life history, formal education and training, work experience, creative thought processes and habits, and specific inventions were conducted with individuals based in Canada's two most economically diverse regions. The first, completed in collaboration with the now defunct French-Canadian inventor's association Le monde des inventions québécoises between 1997 and 1999, involved forty-five Southern Quebec inventors. As it turns out, however, the majority of the interviewees were reluctant to engage in any form of long-distance business relationships with English-speaking individuals because of linguistic deficiencies. In order to address this issue, another round of interviews was conducted between 2006 and 2009 with a group of forty EnglishCanadian inventors in collaboration with the Toronto-based Concept to Creation Cooperative. Unlike the more culturally homogeneous first group, these individuals' backgrounds turned out to be remarkably diverse in light of the fact that several of them were born, educated and often had work experiences in foreign countries. From the evidence gathered and our preparatory and supplemental literature review, we identified three broad, although not mutually exclusive, sets of circumstances through which individuals found new uses or applications for existing products and created new combinations of existing products, processes and materials: 1) by adding to, switching or

\footnotetext{
4 An individual inventor chooses the field in which he works, employs his own resources or acquires them from others who exercise no control over his work, and stands to gain or lose directly from his inventive success or failure. Unlike corporate inventors, an individual inventor typically works with limited resources and with colleagues subject to his guidance and leadership (Jewkes 1969: 72).
} 
adapting specific know-how to other lines of work; 2) by observing something in another line of work and incorporating it into one's own line of work; and 3) through formal and informal multidisciplinary teams working towards the creation of new products and processes. We are reasonably confident that, despite the obvious geographical and size limitations of our empirical study and limits of our literature review, these basic processes are at the roots of virtually all cases of Jacobs spillovers. The following will provide relevant illustrative examples.

Adding to, switching or adapting specific know-how to other lines of work

Benefiting from knowledge gained from previous jobs and tasks was one of the main knowledge spillover mechanisms observed, particularly in light of the very diverse professional backgrounds of the individuals interviewed. A representative case is that of an individual who regularly moved to other fields in search of new challenges and who ended working in the electronics, digital devices and early IT and telephone technologies. Another example is that of an industrial technician who worked in the steel, chemical, aeronautical and armament industries before launching his own ceramic-making business. This widespread pattern of employment across different lines of work seems to be attributable at least in part to the fact that technically creative individuals tend to get bored very quickly with routine work.

Gaining knowledge from other lines of work, however, needs not always imply moving between firms and therefore the mechanism is broader than the generally understood definition of job mobility. Employees may acquire useful knowledge by moving between different divisions within a large firm or when a firm expands into new lines of business.

Whatever the cause, however, this observed widespread pattern of job mobility facilitates the spontaneous transfer of know-how across otherwise seemingly unrelated lines of work. For example, one interesting case involved the transfer of some basic know-how from the newspaper printing business to asphalt production. A recurring problem in the latter line of work was the question of how to clean up residual asphalt found sticking to the inside of tanks after long periods of inactivity. At a particular asphalt firm, people actually climbed into the tank to scrape the residual off, a laborious and equipmentdamaging process. After noticing this, the individual interviewed pointed out to his then new employer that, in the printing business where he had previously been employed, large tanks were cleaned by pouring hot water into them. This technique was tried and eventually proved to be successful, saving the company a significant amount of resources.

Of course, in many (if not most) cases, implementing know-how or ideas in new contexts will typically be but one step towards the creation of a new or improved product or process. Several other ideas, along with a significant amount of development work, will also be required.

Observing know-how and materials and incorporating them in a different production setting 
Sometimes observation and subsequent learning can be sufficient for the creation of interindustrial knowledge spillovers. One such example among our interviewees is a chemical engineer who once worked for a company with plants in remote locations. At the time, his employer needed to reduce his manpower, but was reluctant to do so in isolated plants for fear that employees working alone would be left unattended for several hours if hurt. This individual knew of devices that alerted emergency response personnel when a button was pushed, but this approach would obviously be inadequate if a worker was knocked unconscious. The engineer contacted a company supplying this service and requested that motion detectors be incorporated in their system so that an emergency call would automatically be placed if no motion was detected after a predetermined amount of time. As a result of this new combination, the company was able to save a considerable amount of money without risking the safety of its employees. An additional feature was then added to the system to allow it to work as a burglar alarm when activated by the employee. Our interviewee does not know if similar safety systems are now being used elsewhere, but an article on this particular invention was published in a trade magazine.

Other cases we documented include a shower brush inspired by a car wash brush; a mouse pad arm rest combined with an office chair that was inspired by some classroom furniture; a controllable sled inspired in part by the movements of ice skates; a production shop for a new type of baby bag inspired by the division of labor in a restaurant kitchen; and a device to conduct time studies that drew on ideas from chess clocks, stop watches and computers, among others.

\section{Multidisciplinary team made up of individuals possessing different skills}

Firms are social environments where people with very different backgrounds can interact on a regular basis for the specific purpose of creating new combinations. From the perspective of one inventor interviewed: "If you have experience with one thing, if you are inventor, this is very useful for you. But most useful thing from maybe ... last five years was that I have knowledge, I receive knowledge from other people." After having worked in a number of different firms and industries, he found that learning from colleagues with different skills significantly improved his creative capacities.

Of course, this interpersonal and interdisciplinary aspect of creativity has long made firms interested in promoting cross-functional new product teams (Song et al., 1997). On other occasions though, multidisciplinary teams can be composed of individuals working for different employers and collaborating or providing input on a project, either formally or informally. Thus, the interaction can take place within inter-firm or social networks (Kogut, 2000; Balconi et al., 2004), as well as within intra-firm teams. Again, this basic insight has a long history. For example, J.S. Mill (1848, Book III, Chapter XVII) considered the interaction among persons with dissimilar modes of thought and action one of the primary sources of progress.

One interesting case brought to our attention is a bicycle rack for domestic (or home) use. The inventor interviewed originally got the idea from a friend who pointed out that no such thing existed yet. The reasons for this soon became obvious as he began researching the topic. The rack needed to be light enough to be carried, heavy enough to hold the 
bicycles and prevent thefts, have a nice design, be maintenance-free, and suitable for four bicycles (two adult and two children's bicycles), be they racing or mountain bikes. Finally, it should be affordably priced. A metallic structure would have met most of these requirements, but would have been too heavy to carry. Aluminum was a lighter option, but was too expensive. The inventor then thought of using plastic, but realized quickly that it would be too light. He contacted an industrial draughtsman with whom he had worked with in the past on a specially designed water container for long-distance running. His former collaborator suggested that the rack should be made by blowing rather than casting (i.e., filling a plastic mold) plastic. That way it would be empty inside, which would make it light enough to carry, but heavy enough to hold the bicycles in place after it was filled with water. This solution would finally prove to be the best one. Interestingly enough, although this solution could be seen post facto as a direct implementation of the main principle involved in their previous collaboration, the inventor still needed his previous collaborator to conceive of this approach.

\section{Local Economic Diversity and the Fostering of Jacobs Spillovers}

Assessing the specific impact of large and diversified metropolitan areas on interindustrial knowledge spillovers is not as straightforward as documenting the existence and importance of knowledge spillovers in highly specialized industrial districts. Indeed, in most cases, the new combinations we documented could probably have been developed in many other large urban agglomerations, especially when they were inspired by "non-local" observations such as watching television or traveling. Nonetheless, a number of recurring observations and patterns can be identified from our cases.

The first is that Jacobs spillovers are only one facet of the economic advantages of large and diverse agglomerations. Indeed, just as Jacobs (1969) herself had strongly emphasized, traditional urbanization economies, especially the widespread availability of a broad range of supply goods, were judged crucial by inventors. Individuals who had lived in both a large urban agglomeration and a highly specialized one were especially adamant on this point.

The greater facility of face-to-face interaction between individuals possessing different expertise made possible by close physical proximity was also made abundantly clear to us. The reasons given in this respect ranged from traditional ones, such as establishing trust and jointly addressing innumerable hurdles in development phases, to one that is more specific to Jacobs spillovers, i.e., making sure that individuals with different expertise truly understood each other and that the final product reflected the vision of the project leader. Interestingly, while our interviews spanned a decade which saw drastic improvements in information and communication technologies, electronic communication and the internet did not seem to affect inventors' strong preference for face-to-face interactions and local suppliers. Of course, the fact that the Greater Toronto Area is one of the most economically diversified urban agglomerations in advanced economies certainly played a role in this respect.

Another recurring theme was, not surprisingly, that a large urban agglomeration provides many unplanned learning opportunities by spontaneously allowing creative individuals to 
observe processes and ways of doing things in different contexts. The main channel in this respect seems to be job mobility between different lines of work, a process that is obviously facilitated by the fact that a large and diverse metropolitan area gives creative individuals the possibility to do so without having to relocate their family or lose their friends and social networks. Admittedly, the expertise and capacities possessed by an individual influence the number of possible job opportunities available to him. But while many companies are limited to a specific sector or a few end products, many industrial capacities are generic in nature and can be applied in many different contexts.

Finally, it can be pointed out that some social networks proved especially conducive to Jacobs spillovers, chief among which were the inventors associations themselves. In short, since each individual member's background is limited in various ways, belonging to an association whose members have diverse and complementary expertise typically proves valuable. While opening up to other individuals often proves difficult for inventors, as the limits of their know-how became apparent during the development phase of their invention, they typically became more willing to discuss their ideas as they came to understand the trade-offs between secrecy and the sharing of insights and expertise with individuals whose own know-how was often complementary to theirs. Besides networking with other inventors in order to tap into different skill sets, intellectual stimulation and friendship, an important aspect of these associations is the support their members can provide to each other in terms of locating manufacturers for the supply or fabrication of specific parts, sources of capital and help with marketing and distribution, business and activities that are typically of a more generic nature.

\section{Conclusion}

Economically diversified cities and regions have long been recognized as being more resilient and offering more opportunities than mono or less diversified industrial settings. Despite the fact that specific materials, products and processes have always cut across "industrial sectors," economic specialization has long been held by students of regional growth as the optimal economic setting to promote development and growth. Jacobs (1969), on the other hand, argued that local diversity increases the probability of combining different resources. Indeed, it seems hard to argue against the premise that a diversified city is more likely than a more specialized one to facilitate the transfer of know-how from one area of industry to others that are unrelated in terms of final products. By offering a greater number and variety of problems to be solved, as well as a much wider pool of expert knowledge and other resources, a diversified city can only increase the probabilities of new combinations. More concretely, the exchange of ideas across industries seems to result from a few recurring processes: 1) by adding to, switching or adapting specific know-how to other lines of work; 2) by observing something in another line of work and incorporating it into one's own line of work; and 3) through formal and informal multidisciplinary teams working towards the creation of new products and processes.

It would therefore seem plausible to suggest that, when other things are relatively equal (from taxation levels to the availability of key inputs), a conscious decision on the part of an entrepreneur to locate his venture in a large diversified economy is more likely to 
spontaneously facilitate the absorption of know-how from other economic sectors within his organization. A better understanding of the ways in which creative individuals combine existing resources in different configurations, however, requires that familiar research designs in disciplines such as economics and geography be reconsidered and, at the very least, supplemented by insights that are probably familiar to most readers of this journal. The gains from such an exchange would seem to be twofold. On the one hand the geography of innovation literature can help unveil the effect of regional factors on firms' and individuals' innovative capabilities and hence provide relevant insights for management scholars and entrepreneurs alike. While creativity and innovation are by their nature difficult to manage directly, firms can find ways that indirectly foster them, location choices being one important issue in this regard. On the other hand, creativity has largely been given a background role in the geography of innovation studies. The creativity and innovation management literature can hence in turn shed some light on the micro-foundations of learning which have puzzled urban and regional scholars for some time (Duranton and Puga, 2004).

\section{References}

Audretsch, D. B. (2003) Innovation and Spatial Externalities. International Regional Science Review, 26, 167-174.

Babbage, C. (1832) On the economy of machinery and manufactures, Second edition, Charles Knight, London, UK.

Balconi, M., Breschi, S. and Lissoni, F. (2004) Networks of inventors and the role of academia: an exploration of Italian patent data. Research Policy, 33, 127-145.

Bastiat, Frederic. (2007/1850). The Bastiat collection, Volume 2 (Harmonies of political economy), Ludwig von Mises Institute, Auburn, AL http://mises.org/books/bastiat2.pdf

Beaudry, C. and Schiffauerova, A. (2009) Who's right, Marshall or Jacobs? The localization versus urbanization debate. Research Policy, 38, 318-337.

Berkun, S. (2007) The Myths of Innovation, O’Reilly Media Inc., Sebastopol, CA.

Boschma, R. (2005) Proximity and Innovation: A Critical Assessment. Regional Studies, $39.1 \mathrm{~m} \mathrm{61-74.}$

Breschi, S. and Lissoni, F. (2001) Knowledge Spillovers and Local Innovation Systems: A Critical Survey. Industrial and Corporate Change, 10, 975-1005.

Breschi, S. and Malerba, F. (2001) The Geography of Innovation and Economic Clustering: Some Introductory Notes. Industrial and Corporate Change, 10, 817-833.

Carter, H. D. (1939) If you want to invent, The Vanguard Press, New York, NY. 
Chapman, K. (2005) From "growth centre" to "cluster": Restructuring, regional development, and the Teesside chemical industry. Environment and Planning A, 37.4, 597-615.

Clark, G. L., Feldman M. P., and Gertler M. S. (2000) The Oxford Handbook of Economic Geography, Oxford University Press, Oxford, UK.

Cohen, W.M. and Levinthal, D. (1990) Absorptive capacity: a new perspective on learning and innovation. Administrative Science Quarterly, 35, 128-152.

Csikszentmihalyi, M. (1997) Creativity: Flow and the Psychology of Discovery and Invention, Harper Perennial, New York, NY.

De Bono, E. (1992) Serious Creativity: Using the Power of Lateral Thinking to Create New Ideas, Harper Business, New York, NY.

Duranton, G. and Puga, D. (2004) Micro-foundations of urban agglomeration economies. In Henderson, J. V. and Thisse, J.-F. (eds.), Handbook of Regional and Urban Economics, Vol. 4. Elsevier, Amsterdam, pp. 2063-2117.

Ernst, H. (2002) Success factors of new product development: a review of the empirical literature. International Journal of Management Reviews, 4, 1-40.

Florida, R. (2002) The Rise of the Creative Class: And How it's Transforming Work, Leisure, Community and Everyday Life, Basic Books, New York, NY.

Florida, R. (2005) Cities and the Creative Class, Routledge, New York, NY.

Florida, R. (2008) Who's Your City? How the Creative Economy is Making Where to Live the Most Important Decision of Your Life, Basic Books, New York, NY.

Fores, M. (1979) The history of technology: An alternative view. Technology and Culture, 20.4, 853-860.

Gassmann, O. and Zeschky, M. (2008) Opening up the Solution Space: The Role of Analogical Thinking for Breakthrough Product Innovation. Creativity and Innovation Management, 17, 97-106.

Gertler, M. (2003) Tacit knowledge and the economic geography of context, or The undefinable tacitness of being (there). Journal of Economic Geography, 3, 75-99.

Glaeser, E. L., Kallal, H. D., Scheinkman, J. A. and Shleifer, A. (1992) Growth in Cities. The Journal of Political Economy, 100, 1126-1152.

Hall, P. (2000) Creative Cities and Economic Development. Urban Studies, 37, 639-649. 
Hansen, N. (2002) Dynamic externalities and spatial innovation diffusion: implications for peripheral regions. International Journal of Technology, Policy and Management, 2, 260-271.

Hoover, E. M. and Giarratani, F. (1984) An Introduction to Regional Economics, Third edition, Alfred A. Knopf, New York, NY.

Hospers, G. J. and Pen, C. J. (2008) A View of Creative Cities Beyond the Hype. Creativity and Innovation Management, 17.4, 259-270.

Howe, Frederic Clemson. (1915). The Modern City and Its Problems. Charles Scribner's Sons, New York, NY.

http://books.google.com/books?id=myQbAAAAYAAJ\&dq=howe+1915+the+modern+ci ty+and+its+problems\&source=gbs_navlinks_s

Jacobs, J. (1969) The Economy of Cities, Random House, New York, NY.

Kaufmann, G. (2004) Two Kinds of Creativity - But Which Ones? Creativity and Innovation Management, 13, 154-165.

Keir, M. (1919) The Localization of Industry: How it Starts; Why it Grows and Persists. The Scientific Monthly, 8.1, 32-48.

Koestler, A. (1969/1964) The act of creation, Hutchinson of London, London, UK.

Kogut, B. (2000) The Network as Knowledge: Generative Rules and the Emergence of Structure, Strategic Management Journal, 21, 405-425.

Krzyzanowski, W. (1927) Review of the Literature of the Location of Industries. Journal of Political Economy, 35, 278-291.

Lampard, E. (1955) The History of Cities in the Economically Advanced Areas. Economic Development and Cultural Change, 3.1, 81-136.

Landau, R. (1996) Entrepreneurs, Managers, and the Importance of Finance. Daedalus, 125.2, 19-37.

Lipsey, R. G., Carlaw, K. I. and Bekar, C. T. (2005) Economic Transformations: General Purpose Technologies and Long-Term Economic Growth. Oxford University Press, Oxford, UK.

Lissoni, F. (2001) Knowledge codification and the geography of innovation: the case of Brescia mechanical cluster. Research Policy, 30, 1479-1500. 
Lucas, R. E. (1988) On the mechanics of economic development. Journal of Monetary Economics, 22, 3-42.

Marshall, A. (1920) Principles of Economics, eighth edition, MacMillan, London, UK. Mill, J. S. (1848) Principles of Political Economy with some of their Applications to Social Philosophy, Seventh edition, Longmans, Green and Co., London, UK.

Moulaert, F and Sekia, F. (2003). Territorial Innovation Models: A Critical Survey. Regional Studies, 37.3, 289-302.

Nooteboom, B. (2000). Learning by Interaction: Absorptive Capacity, Cognitive Distance and Governance. Journal of Management and Governance, 4, 69-92.

Polese, M. (2005) Cities and National Economic Growth: A Reappraisal. Urban Studies, 42, 1429-1451.

Porter, M. (1990) The Competitive Advantage of Nations, The Macmillan Press, London, UK.

Schroeder, R. G., Van de Ven, A. H., Scudder, G. D. and Polley, D. (1989) The development of innovation ideas. In Van de Ven, A. H., Angle, H. L. and Poole, M. S. (eds.), Research on the management of innovation: The Minnesota studies. Harper and Row Publishers, New York, NY, pp. 107-134.

Scott, A. J. (2006) Creative Cities: Conceptual Issues and Policy Questions. Journal of Urban Affairs, 28.1, 1-17.

Simmie, J. (2005) Innovation and Space: A Critical Review of the Literature. Regional Studies, 39.6, 789-804.

Song, X. M., Montoya-Weiss, M. M. and Schmidt, J. B. (1997) Antecedents and Consequences of Cross-Functional Cooperation: A Comparison of R\&D, Manufacturing, and Marketing Perspectives. Journal of Product Innovation Management, 14, 35-47.

Sternberg, R. J. (Ed.) (1999) Handbook of Creativity, Cambridge University Press, Cambridge, UK.

Twiss, B. C. (1980/1974) Managing technological innovation, Longman, London, UK.

Weber, R. J. and Perkins, D. N. (1992) Inventive minds: Creativity in technology, Oxford University Press, New York, NY.

Weitzman, M. L. (1998) Recombinant Growth. The Quarterly Journal of Economics, 113, 331-360. 